Article

\title{
The In Vitro Effects of Pentamidine Isethionate on Coagulation and Fibrinolysis
}

\author{
Rami A. Al-Horani ${ }^{1} * \mathbb{E}$, Daytriona Clemons ${ }^{1}$ and Madhusoodanan Mottamal ${ }^{2}$ \\ 1 Division of Basic Pharmaceutical Sciences, College of Pharmacy, Xavier University of Louisiana, \\ New Orleans, LA 70125, USA; dclemons@xula.edu \\ 2 Department of Chemistry, Xavier University of Louisiana, New Orleans, LA 70125, USA; \\ mMottama@xula.edu \\ * Correspondence: ralhoran@xula.edu; Tel.: +1-504-520-7603; Fax: +1-504-520-7954
}

Received: 17 May 2019; Accepted: 30 May 2019; Published: 6 June 2019

\begin{abstract}
Pentamidine is bis-oxybenzamidine-based antiprotozoal drug. The parenteral use of pentamidine appears to affect the processes of blood coagulation and/or fibrinolysis resulting in rare but potentially life-threatening blood clot formation. Pentamidine was also found to cause disseminated intravascular coagulation syndrome. To investigate the potential underlying molecular mechanism(s) of pentamidine's effects on coagulation and fibrinolysis, we studied its effects on clotting times in normal and deficient human plasmas. Using normal plasma, pentamidine isethionate doubled the activated partial thromboplastin time at $27.5 \mu \mathrm{M}$, doubled the prothrombin time at $45.7 \mu \mathrm{M}$, and weakly doubled the thrombin time at $158.17 \mu \mathrm{M}$. Using plasmas deficient of factors VIIa, IXa, XIa, or XIIa, the concentrations to double the activated partial thromboplastin time were similar to that obtained using normal plasma. Pentamidine also inhibited plasmin-mediated clot lysis with half-maximal inhibitory concentration $\left(\mathrm{IC}_{50}\right)$ value of $\sim 3.6 \mu \mathrm{M}$. Chromogenic substrate hydrolysis assays indicated that pentamidine inhibits factor Xa and plasmin with $\mathrm{IC}_{50}$ values of $10.4 \mu \mathrm{M}$ and $8.4 \mu \mathrm{M}$, respectively. Interestingly, it did not significantly inhibit thrombin, factor XIa, factor XIIIa, neutrophil elastase, or chymotrypsin at the highest concentrations tested. Michaelis-Menten kinetics and molecular modeling studies revealed that pentamidine inhibits factor $\mathrm{Xa}$ and plasmin in a competitive fashion. Overall, this study provides quantitative mechanistic insights into the in vitro effects of pentamidine isethionate on coagulation and fibrinolysis via the disruption of the proteolytic activity of factor Xa and plasmin.
\end{abstract}

Keywords: pentamidine; factor Xa; plasmin; coagulation; fibrinolysis

\section{Introduction}

Pentamidine isethionate (Figure 1) is an antimicrobial drug that is used parenterally or by inhalation for the treatment of African trypanosomiasis, babesiosis, and leishmaniasis. Given its strong basic characteristics, pentamidine does not significantly cross the blood brain barrier, and thus, it is only used for the early stage of African trypanosomiasis at which there is no central nervous system involvement [1-3]. It is also used in the treatment of Pneumocystis jirovecii pneumonia which is a major opportunistic infection in immune compromised patients including patients with acquired immunodeficiency disease [4].

Parenteral administration of pentamidine should be cautiously performed in patients with pre-existing bone marrow depression or blood dyscrasias. In fact, complete blood count should be performed before, periodically during, and after therapy. This is, in part, because pentamidine is associated with significant hematological toxicities including leukopenia $(10 \%)$, thrombocytopenia $(3 \%)$, anemia $(1 \%)$, neutropenia, and pancytopenia [5]. Rare but potentially life-threatening blood clot 
formation has also been observed in less than $1 \%$ of treated patients. The development of disseminated intravascular coagulation following pentamidine administration was also reported [6].

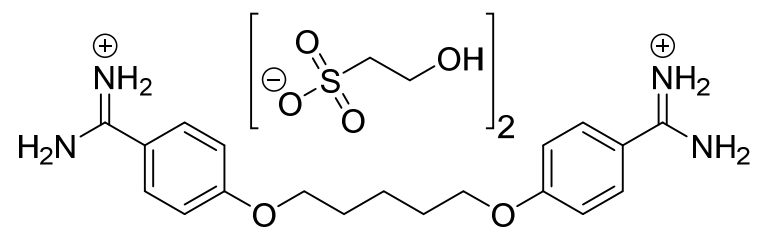

Figure 1. Chemical structure of pentamidine isethionate. Pentamidine is the active constituent and is chemically known as 4,4'-(pentane-1,5-diylbis(oxy))-dibenzimidamide.

Previous in vitro studies indicated that pentamidine isethionate dose-dependently inhibits platelet function. At concentrations greater than $8.4 \mu \mathrm{M}$, pentamidine completely inhibited platelet-aggregation induced by adenosine diphosphate, epinephrine, thrombin, and collagen as well as partially inhibited retention and clot retraction in platelet-rich plasmas. Likewise, pentamidine was reported to prolong clotting times at concentrations greater than $8.4 \mu \mathrm{M}$ [7].

In this report, we investigated the potential in vitro molecular mechanisms of pentamidine isethionate effects on coagulation and fibrinolysis. We quantitatively examined the effect of this drug on the activated partial thromboplastin time (APTT) using normal human plasma as well as deficient plasmas of certain coagulation factors. Furthermore, we quantified the effect of the drug on prothrombin time (PT) and thrombin time (TT) in normal human plasmas. We also in vitro quantified the effect of pentamidine isethionate on plasmin-mediated clot lysis. The inhibitory potential of pentamidine isethionate towards coagulation proteins (human thrombin and factors Xa, XIa, and XIIIa), fibrinolysis protease (human plasmin), digestive proteases (bovine trypsin and chymotrypsin), and inflammatory protease (human neutrophil elastase) was also studied. As a result, we report that pentamidine isethionate doubled the APTT, PT, and TT at concentrations of 27.88, 45.70, and 158.17, respectively. It inhibited the plasmin-mediated clot lysis with $\mathrm{IC}_{50}$ value of $3.6 \pm 1.5 \mu \mathrm{M}$ and efficacy of $58.3 \pm 8.9 \%$. Pentamidine isethionate was found to be a moderately potent inhibitor of human factor Xa (FXa), a serine protease of the common coagulation pathway, and of human plasmin, a serine protease of fibrinolysis, with $\mathrm{IC}_{50}$ values of $10.4 \pm 0.8 \mu \mathrm{M}$ and $8.4 \pm 0.8 \mu \mathrm{M}$, respectively. Michaelis-Menten kinetics and molecular modeling studies indicated that pentamidine inhibits the two enzymes competitively by targeting select amino acid residues in the enzymes' active sites.

\section{Materials and Methods}

\subsection{Chemicals, Reagents, Enzymes, and Substrates}

Pentamidine isethionate was purchased from Millipore-Sigma (St. Louis, MO, USA). Reagents for clotting assays including thromboplastin-D, APTT reagent, and thrombin time reagent were all from Fisher Scientific (Pittsburgh, PA, USA). Chemicals used to prepare enzyme assay buffers were from Millipore-Sigma or Fisher Scientific. N,N-dimethylcasein, dansylcadaverine, and dithiothreitol were also from Millipore-Sigma. All types of plasmas were purchased from George King Bio-Medical, Inc. (Overland Park, KS, USA). Coagulation enzymes including thrombin, factor Xa (FXa), factor XIa (FXIa), and factor XIIIa (FXIIIa) were from Haematologic Technologies, Inc. (Essex Junction, VT, USA). Digestive enzymes including trypsin and chymotrypsin were from Millipore-Sigma. Neutrophil elastase was from Elastin Products Company (Owensville, MO, USA). Chromogenic substrates: Spectrozyme TH, Spectrozyme FXa, and Spectrozyme PL, were obtained from Biomedica-Diagnostics (Windsor, NS, Canada). FXIa chromogenic substrate (S-2366) and trypsin substrate (S-2222) were obtained from Diapharma (West Chester, OH, USA). Chromogenic substrate for chymotrypsin (N-Succinyl-Ala-Ala-Pro-Phe- $p$-nitroanilide) and that for neutrophil elastase (S-1384) were from Millipore-Sigma. 


\subsection{In vitro Effect on Clotting Times of Human Plasmas}

Effect of pentamidine isethionate on clotting times of normal human plasma was evaluated in a standard one-stage assay using BBL Fibrosystem fibrometer (Becton-Dickinson, Sparles, MD, USA), as described previously [8,9]. For the PT assay, thromboplastin-D was reconstituted according to the manufacturer's directions and warmed to $37^{\circ} \mathrm{C}$. A volume of $10 \mu \mathrm{L}$ of variable concentrations of pentamidine isethionate was brought up to $100 \mu \mathrm{L}$ with citrated human plasma, incubated for 30 sec at $37^{\circ} \mathrm{C}$ followed by the addition of $200 \mu \mathrm{L}$ of prewarmed thromboplastin-D, and the time to clotting was noted. For the APTT assay, $10 \mu \mathrm{L}$ of variable concentrations of pentamidine isethionate was mixed with $90 \mu \mathrm{L}$ of citrated human plasma and $100 \mu \mathrm{L}$ of prewarmed APTT reagent $(0.2 \%$ ellagic acid). After incubation for $4 \mathrm{~min}$ at $37^{\circ} \mathrm{C}$, clotting was initiated by adding $100 \mu \mathrm{L}$ of prewarmed $25 \mathrm{mM} \mathrm{CaCl}_{2}$ and the time to clotting was noted. For the TT assay, $10 \mu \mathrm{L}$ of variable concentrations of pentamidine isethionate was brought up to $200 \mu \mathrm{L}$ with citrated human plasma, incubated for $3 \mathrm{~min}$ at $37^{\circ} \mathrm{C}$ followed by the addition of $100 \mu \mathrm{L}$ of prewarmed thrombin time reagent, and the time to clotting was noted. The data were fit to a quadratic trendline, which was used to determine the concentration of pentamidine isethionate necessary to double the clotting time. Clotting times in the absence of pentamidine isethionate were determined in a similar fashion using $10 \mu \mathrm{L}$ of highly purified water and were found to be $14.9 \pm 0.5 \mathrm{~s}$ for PT, $31.4 \pm 0.5 \mathrm{~s}$ for APTT, and $9.6 \pm 0.1 \mathrm{~s}$ for TT. To determine the in vitro effect on the APTT of deficient human plasmas, the APTT assay was repeated, using human plasmas deficient of factor VII (FVII), factor IX (FIX), FXI, or factor XII (FXII). Isethionic acid did not affect the APTT at the highest concentration tested of $33.3 \mathrm{mM}$. The positive control used in APTT and PT assays was rivaroxaban, a clinically used FXa inhibitor. Under the conditions reported, rivaroxaban doubled the APTT and PT at concentrations of $0.123 \pm 0.003 \mu \mathrm{M}$ and $0.193 \pm 0.043 \mu \mathrm{M}$, respectively.

\subsection{In Vitro Effect on Fibrinolysis}

The method followed here was similar to that reported earlier [10]. This in vitro experiment was conducted in 96-well platform in $\mathrm{pH} 7.4$ buffer at $25^{\circ} \mathrm{C}$. The clot was generated by the addition of $80 \mu \mathrm{L}$ of a solution of human thrombin $(2.5 \mu \mathrm{g} / \mathrm{mL})$ in $20 \mathrm{mM}$ TrisHCl buffer containing $10 \mathrm{mM}$ $\mathrm{CaCl}_{2}$ to $60 \mu \mathrm{L}$ of a solution of fibrinogen $(10 \mathrm{mg} / \mathrm{mL})$ and FXIIIa $(2 \mu \mathrm{g} / \mathrm{mL})$ in $20 \mathrm{mM}$ TrisHCl buffer containing $10 \mathrm{mM} \mathrm{CaCl}_{2}$. The resulting clot was stabilized for $15 \mathrm{~min}$ at $25^{\circ} \mathrm{C}$. The absorbance was then measured at $405 \mathrm{nM}$ and was $\sim 0.98$ across all wells. Following, $5 \mu \mathrm{L}$ of pentamidine isethionate (or water) (effective concentrations in the well were 0-1900 $\mu \mathrm{M}$ ) was added to each well resulting in no significant change in the A405 of the corresponding wells. Finally, $5 \mu \mathrm{L}$ of human plasmin (stock of $1.6 \mu \mathrm{M}$ ) in $20 \mathrm{mM}$ TrisHCl buffer of $\mathrm{pH} 7.4$ containing $2.5 \mathrm{mM} \mathrm{CaCl}_{2}$ and $100 \mathrm{mM} \mathrm{NaCl}$ was added to each well and the A405 of each well was recorded over more than $340 \mathrm{~min}$ at various time intervals. By semilog plotting the rate of clot lysis (fibrinolysis) over the time period of 5-100 min versus the corresponding concentrations of pentamidine isethionate using the logistic Equation (1), the $\mathrm{IC}_{50}$ of fibrinolysis inhibition and the inhibition efficacy were determined. In this equation, $\mathrm{Y}$ is the percentage ratio of clot lysis in the presence of pentamidine isethionate to that in its absence, $Y_{M}$ and $Y_{0}$ are the maximum and minimum possible values of the clot lysis (\%), $\mathrm{IC}_{50}$ is the concentration of the test molecule inhibitor that results in 50\% inhibition of clot lysis, and HS is the Hill slope.

$$
Y=Y_{0}+\frac{Y_{M}-Y_{0}}{1+10^{\left(\log [I]_{0}-\log I C_{50}\right)(H S)}}
$$

\subsection{Effect of Pentamidine Isethionate on Common Coagulation Pathway and Fibrinolysis Enzymes}

Direct inhibition of human FXa and $\alpha$-thrombin of the common coagulation pathway and human plasmin of the fibrinolysis pathway were measured using the corresponding chromogenic substrate hydrolysis assays at $37^{\circ} \mathrm{C}$ and $\mathrm{pH} 7.4$, as reported earlier using the 96-microplate platform [8-12]. In FXa assay, each well of a 96-well microplate generally contained $185 \mu \mathrm{L} \mathrm{pH} 7.4$ buffer to which $5 \mu \mathrm{L}$ pentamidine isethionate (or purified water) and $5 \mu \mathrm{L}$ FXa (43.5 nM stock conc.) were sequentially 
added. After $10 \mathrm{~min}$ incubation, $5 \mu \mathrm{L}$ Spectrozyme FXa ( $5 \mathrm{mM}$ stock conc.) was rapidly added and the residual activity of FXa was measured from the initial rate of increase in absorbance at $405 \mathrm{nM}$. The relative residual enzyme activity at each concentration of pentamidine isethionate was calculated from the ratio of enzyme activity in the presence and absence of the test molecule. The concentration vs effect curve was constructed using logistic Equation (1) from which the potency ( $\mathrm{IC}_{50}$ ) and efficacy $(\Delta Y)$ of inhibition were also obtained. In Equation (1), $Y$ is the percentage ratio of residual enzyme activity in the presence of pentamidine isethionate to that in its absence, $Y_{M}$ and $Y_{0}$ are the maximum and minimum possible values of the residual $\mathrm{FXa}$ activity $(\%), \mathrm{IC}_{50}$ is the concentration of the test molecule that results in 50\% inhibition of FXa activity.

For thrombin and plasmin, the assays were performed using substrates appropriate for each enzyme (Spectrozyme TH for thrombin and Spectrozyme PL for plasmin) under conditions closest to the physiological condition. The $\mathrm{K}_{\mathrm{M}}$ of the substrate for its enzyme was used to identify the concentration of the substrate to be used for inhibition studies. For thrombin assay, each well of a 96-well microplate generally contained $185 \mu \mathrm{L} \mathrm{pH} 7.4$ buffer to which $5 \mu \mathrm{L}$ pentamidine isethionate (or reference) and $5 \mu \mathrm{L}$ thrombin (240 nM stock conc.) were sequentially added. After 10 min incubation, $5 \mu L$ Spectrozyme TH (1.0 mM stock conc.) was rapidly added and the residual activity of thrombin was measured from the initial rate of increase in absorbance at $405 \mathrm{nM}$. For plasmin assay, each well of a 96-well microplate generally contained $85 \mu \mathrm{L} \mathrm{pH} 7.4$ buffer to which $5 \mu \mathrm{L}$ pentamidine isethionate (or purified water) and $5 \mu \mathrm{L}$ plasmin (500 nM stock conc.) were sequentially added. After 10 min incubation, $5 \mu \mathrm{L}$ Spectrozyme PL (1.0 mM stock conc.) was rapidly added and the residual activity of plasmin was measured from the initial rate of increase in absorbance at $405 \mathrm{nM}$. The potency and efficacy of plasmin inhibition by pentamidine isethionate were calculated as above. Buffer for assays was $20-50 \mathrm{mM}$ Tris- $\mathrm{HCl}$ buffer, $\mathrm{pH}$ 7.4, containing 100-150 mM NaCl, $2.5 \mathrm{mM} \mathrm{CaCl}_{2}, 0.1 \%$ PEG8000, and 0.02\% Tween80. All assays were performed three times.

\subsection{Effect of Pentamidine Isethionate on Related Enzymes}

Direct inhibition of a panel of human serine proteases including the coagulation protease FXIa, the inflammation protease neutrophil elastase, and the digestive proteases trypsin and chymotrypsin by pentamidine isethionate was also evaluated using the corresponding chromogenic substrate hydrolysis assays in a 96-well microplate format adapted from the literature [8-13]. Direct inhibition of the human coagulation transglutaminase FXIIIa was also studied using a fluorescence-based transglutamination assay as reported in the literature [14,15].

For the FXIa assay, each well of a 96-well microplate generally contained $85 \mu \mathrm{L} \mathrm{pH} 7.4$ buffer to which $5 \mu \mathrm{L}$ pentamidine isethionate and $5 \mu \mathrm{L}$ plasma FXIa (15.3 nM stock conc.) were sequentially added. After $10 \mathrm{~min}$ incubation, $5 \mu \mathrm{L}$ FXIa substrate $(6.9 \mathrm{mM}$ stock concentration) was rapidly added and the residual FXIa activity was measured from the initial rate of increase in absorbance at $405 \mathrm{nM}$. Assays were performed in similar fashion with trypsin and chymotrypsin. Stock concentrations used were $18.9 \mu \mathrm{g} / \mathrm{mL}$ (trypsin) and $22.7 \mathrm{mM}$ (S-2222) for bovine trypsin assay (final volume was $200 \mu \mathrm{L}$ ) and $2 \mu \mathrm{g} / \mathrm{mL}$ (chymotrypsin) and $16.2 \mathrm{mM}$ (N-Succinyl-Ala-Ala-Pro-Phe- $p$-nitroanilide) for bovine chymotrypsin assay (final volume was $200 \mu \mathrm{L}$ ). The buffer used for FXIa, trypsin, chymotrypsin assays was $50 \mathrm{mM}$ Tris- $\mathrm{HCl}$ buffer, $\mathrm{pH} 7.4$, containing $150 \mathrm{mM} \mathrm{NaCl}, 2.5 \mathrm{mM} \mathrm{CaCl}_{2}, 0.1 \%$ PEG8000, and 0.02\% Tween80. Neutrophil elastase inhibition assay was performed in a 96-well plate with a final volume of $100 \mu \mathrm{L}$ with $0.125 \mathrm{M}$ 4-(2-hydroxyethyl)-1-piperazineethanesulfonic acid (HEPES) buffer, pH 7.4 containing $0.125 \%$ Triton- $X 100$, as reported earlier [13]. To each well containing $88 \mu \mathrm{L}$ of the buffer was added $4 \mu \mathrm{L}$ neutrophil elastase ( $2 \mu \mathrm{M}$ stock conc.) and $5 \mu \mathrm{L}$ pentamidine isethionate. After incubation, $3 \mu \mathrm{L}$ neutrophil elastase substrate (S-1384; $25 \mathrm{mM}$ stock conc.) was rapidly added and the residual enzyme activity measured from the initial rate of increase in the absorbance at $405 \mathrm{~nm}$.

For the FXIIIa assay, $1 \mu \mathrm{L}$ of pentamidine isethionate was diluted with $87 \mu \mathrm{L}$ of pH 7.4 buffer (50 mM Tris- $\mathrm{HCl}, 1 \mathrm{mM} \mathrm{CaCl}_{2}, 100 \mathrm{mM} \mathrm{NaCl}$, and $2 \mathrm{mg} / \mathrm{mL} N, N$-dimethylcasein) and $5 \mu \mathrm{L}$ dithiothreitol $(20 \mathrm{mM})$ at $37^{\circ} \mathrm{C}$, followed by the addition of $2 \mu \mathrm{L}$ human FXIIIa $(0.3 \mu \mathrm{M})$ and incubation for $10 \mathrm{~min}$. 
The activity of FXIIIa was evaluated by the addition of $5 \mu \mathrm{L}$ dansylcadaverine $(2 \mathrm{mM})$ and measuring the initial rate of increase in fluorescence emission $\left(\lambda_{\mathrm{Ex}}=360 \mathrm{nM}\right.$ and $\left.\lambda_{\mathrm{Em} .}=490 \mathrm{nM}\right)$. In all assays, the dose dependence of the fractional residual enzyme activity, if any, was analyzed using Equation (1) above to obtain the apparent concentration of the test molecule required to reduce the enzyme activity to $50 \%$ of its initial value $[14,15]$. All assays were performed three times.

2.6. Michaelis-Menten Kinetics for Chromogenic Substrates Hydrolysis by FXa and Plasmin in the Presence of Pentamidine Isethionate

The initial rate of Spectrozyme FXa hydrolysis by human FXa $(87 \mathrm{nM})$ or that of Spectrozyme PL hydrolysis by human plasmin $(120 \mathrm{nM})$ was monitored from the linear increase in absorbance at $405 \mathrm{nM}$ corresponding to less than $10 \%$ consumption of the substrate. The initial rate was measured as a function of various concentrations of the substrate $(0-500 \mu \mathrm{M})$ in the presence of fixed concentration of pentamidine isethionate $(0-100 \mu \mathrm{M})$ in $20-50 \mathrm{mM}$ TrisHCl buffer, $\mathrm{pH} 7.4$, containing $100-150 \mathrm{mM} \mathrm{NaCl}$, $2.5 \mathrm{mM} \mathrm{CaCl}_{2}, 0.1 \%$ PEG8000, and $0.02 \%$ Tween 80 at $37^{\circ} \mathrm{C}$. The data were fitted by Michaelis-Menten Equation (2) to determine $\mathrm{K}_{\mathrm{M}}$ (substrate affinity to the enzyme) and $\mathrm{V}_{\mathrm{MAX}}$ (maximum velocity of enzyme reaction).

$$
V_{i}=\frac{V_{M A X} \times[S]}{K_{M}+[S]}
$$

\subsection{Molecular Modeling of Pentamidine Binding to the Active Site of Human FXa and Plasmin}

Molecular docking studies were performed to evaluate the binding mode of pentamidine to the active sites of human FXa and plasmin using Schrodinger's (Suite 2015-3) Glide 6.8 program [16]. We used the coordinates of FXa from the co-crystal structure of FXa-DX-9065a complex (PDB ID:1FAX) [17]. Likewise, the coordinates of plasmin were retrieved from the ternary complex of microplasmin-staphylokinase-microplasmin which also includes the modified tripeptide GluGlyArg-chloromethyl-ketone (PDB ID:1BUI) [18]. The structures of FXa and plasmin were prepared by removing crystallographic water molecules beyond $5 \AA$ from the ligand and adding hydrogen atoms consistent with the physiologic $\mathrm{pH}$ of 7.0 using Maestro 10.3 of Schrodinger Suite. In the case of plasmin, covalent bonds of the inhibitor to the amino acid residues His57 and Ser195 were also deleted. Subsequently, the protein structures were energy minimized with a root-mean-square deviation (RMSD) cutoff value of $0.3 \AA$ for all heavy atoms. Initial coordinates for pentamidine were extracted from ZINC database [19] and the molecule was prepared by energy minimization using the Schrodinger Suite. The co-crystallized ligand region and the area surrounding it was specified as the ligand binding site, and the receptor grids for each target protein was generated using the OPLS3 forcefield [20]. The grid center was set to be the centroid of the co-crystal ligand, with a cubic grid box of $10 \AA$ on each side. No constraints were used in any of the receptor grid generations. The docking calculations were done using the default parameters under the standard precision mode. All the poses were subjected to post-docking minimization. The best-docked structure based on the docking score was selected for subsequent analysis.

\section{Results}

\subsection{Pentamidine Affects the Clotting Times of Human Plasma and the Effect Is Independent of Factors VIIa,} $I X a, X I a$, and XIIa

Plasma clotting assays including APTT, PT, and TT are routinely used to assess the potential effect of molecules on the coagulation process in an in vitro setting. The APTT assay typically measures the effect of molecules on the intrinsic pathway of coagulation which involves FXIIa, FXIa, and FIXa, in addition to the effect on the common coagulation pathway, particularly on thrombin and FXa. Likewise, the PT assay evaluates the effect of molecules on the extrinsic pathway of coagulation involving FVIIa, in addition to the effect on the common pathway. The TT screens the effect on 
the formation of fibrin from fibrinogen after the addition of known amounts of thrombin to the plasma sample [21]. The concentrations of pentamidine required to double APTT, PT, and TT were measured, as described earlier [8,9]. Figure 2 shows the variations in the three clotting times in the presence of varying concentrations of pentamidine isethionate. A two-fold increase in the APTT required $27.88 \pm 2.99 \mu \mathrm{M}$ from pentamidine isethionate in human plasma containing all clotting factors. Interestingly, the two-fold increase in the APTT using plasmas deficient of FVII, FIX, FXI, or FXII was achieved with similar concentrations (Table 1). This suggests that the effect of pentamidine isethionate on the APTT is independent of FVIIa, FIXa, FXIa, or FXIIa. Likewise, a two-fold increase in the PT and TT required $45.70 \pm 0.85 \mu \mathrm{M}$ and $158.17 \pm 30.87 \mu \mathrm{M}$ of pentamidine isethionate, respectively. Under the reported conditions, isethionic acid did not affect the APTT in normal human plasma at the highest concentration tested of $33.3 \mathrm{mM}$. Rivaroxaban, a clinically used FXa inhibitor, doubled the APTT and PT at concentrations of $0.123 \pm 0.003 \mu \mathrm{M}$ and $0.193 \pm 0.043 \mu \mathrm{M}$, respectively, which is consistent with reported values [22-24]. These results indicate that pentamidine more effectively prolongs the APTT and PT in in vitro setting. Furthermore, the dual effect on APTT and PT and the lack of statistically significant changes in the concentration required to double the APTT in plasmas deficient of clotting factors of intrinsic and extrinsic pathways indicate that the effect of pentamidine can be attributed to effect(s) on proteins in the common coagulation pathway, namely thrombin and/or FXa. Nevertheless, the two-fold increase in TT required a relatively high concentration of $>150 \mu \mathrm{M}$ in normal plasma which subsequently suggests that the effect of pentamidine on clotting times may be primarily attributed to FXa inhibition. It is worth to mention here that the positive control rivaroxaban has no effect on TT [22-24].

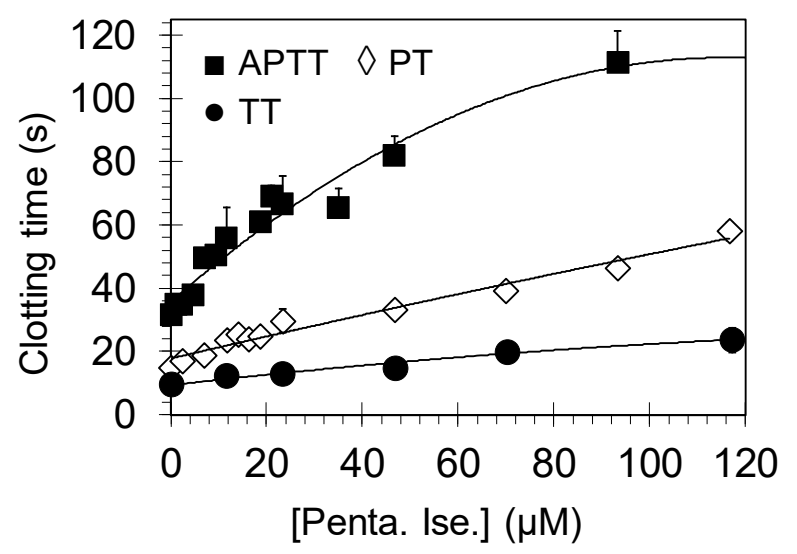

Figure 2. Effect of pentamidine isethionate on the clotting times of APTT, PT, and TT in normal human plasma. Shown is the prolongation of clotting time as a function of pentamidine isethionate concentration $(0-120 \mu \mathrm{M})$ in either APTT assay $(\bullet)$, PT assay $(\diamond)$, or TT assay $(\bullet)$. Solid lines are trend lines from which the concentration necessary to double the clotting time was deduced. Given also are the standard error bars $( \pm 1$ SE). Penta. Ise. = Pentamidine isethionate.

Table 1. The effect of pentamidine isethionate on the clotting times (APTT, PT, and TT) of different human plasmas. ${ }^{\text {a) }}$

\begin{tabular}{cc}
\hline Type of Human Plasma & $\begin{array}{c}\text { [Pentamidine Isethionate] } \\
(\mu \mathrm{m}) \text { to Double Clotting Time }\end{array}$ \\
\hline APTT assay & APTT $_{\mathrm{EC} 2 \times}$ \\
Normal & $\left.27.88^{\mathrm{b})} \pm 2.99 \mathrm{c}\right)$ \\
Deficient of FVII & $26.71 \pm 0.50$ \\
Deficient of FIX & $26.32 \pm 3.52$ \\
Deficient of FXI & $29.48 \pm 3.88$ \\
Deficient of FXII & $27.05 \pm 6.05$ \\
\hline
\end{tabular}


Table 1. Cont.

\begin{tabular}{cc}
\hline Type of Human Plasma & $\begin{array}{c}\text { [Pentamidine Isethionate] } \\
(\mu \mathrm{m}) \text { to Double Clotting Time }\end{array}$ \\
\hline PT assay & PT $_{\mathrm{EC} 2 \times}$ \\
Normal & $45.70 \pm 0.85$ \\
\hline TT assay & TT $_{\mathrm{EC} 2 \times}$ \\
Normal & $158.17 \pm 30.87$
\end{tabular}

Note: a) Prolongation of clotting times as a function of concentration of pentamidine isethionate in APTT, PT, and TT assays, ${ }^{\text {b) }}$ The effective concentrations of pentamidine isethionate required to double the clotting times when coagulation triggered by the intrinsic pathway $\left(\mathrm{APTT}_{\mathrm{EC} 2 \times}\right)$, the extrinsic pathway $\left(\mathrm{PT}_{\mathrm{EC} 2 \times}\right)$, and thrombin $\left(\mathrm{TT}_{\mathrm{EC} 2 \times}\right)$. In each case, the concentration is the average of three trials, ${ }^{c}$ Errors represent \pm 1 S.E.

\subsection{Pentamidine Dose-Dependently Inhibits Plasmin-Mediated Clot Lysis}

A key experiment to evaluate the effect of pentamidine isethionate on the clot lysis is the in vitro plasmin-mediated clot fibrinolysis assay in a 96-well platform [10]. A thrombin-induced fibrin-rich clot was first generated by inducing fibrinogenolysis using human thrombin and FXIIIa in $20 \mathrm{mM}$ TrisHCl, pH 7.4, containing $10 \mathrm{mM} \mathrm{CaCl}_{2}$ at $25^{\circ} \mathrm{C}$. The resulting clot was allowed to stabilize for 15 min, following which, pentamidine isethionate (or water) at desired concentrations was added and allowed to equilibrate. Finally, clot lysis was initiated by the addition of human plasmin and was monitored by measuring absorbance at $405 \mathrm{nM}$ as a function of time. Plasmin-mediated hydrolysis of the fibrin-rich clot resulted in a decrease in the relative A405 over time. Under the conditions studied, the clot was completely lysed in the absence of pentamidine isethionate in $340 \mathrm{~min}$. Yet, a significant inhibition of clot lysis was detected in the presence of pentamidine isethionate in a dose-dependent manner. Plotting the rate of clot lysis (i.e., fibrinolysis) over 5-100 min versus the corresponding concentrations of pentamidine isethionate shows a semilog sigmoidal relationship, which could be analyzed using dose-response Equation (1) to calculate the $\mathrm{IC}_{50}$ of fibrinolysis inhibition. An apparent $\mathrm{IC}_{50}$ of $3.6 \pm 1.5 \mu \mathrm{M}$ and efficacy of $58.3 \pm 8.9 \%$ (Figure 3) was calculated using this non-linear regressional analysis.

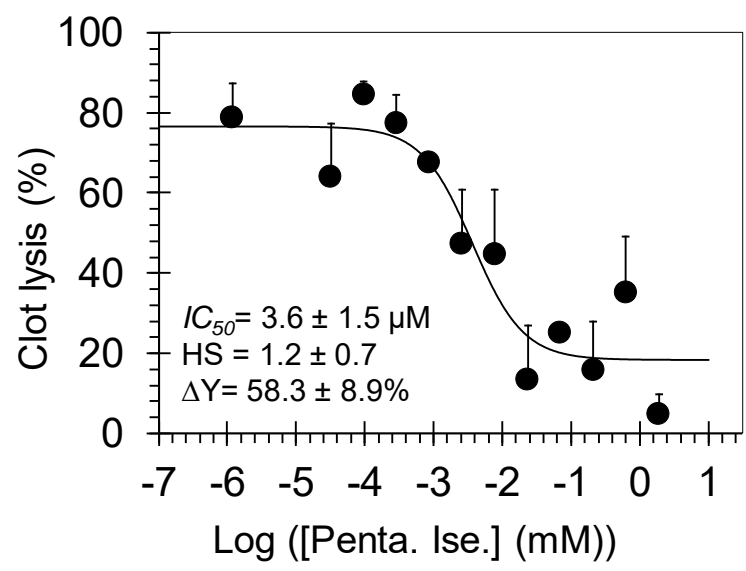

Figure 3. The dose-dependent inhibition of plasmin-mediated clot lysis by pentamidine isethionate. The effect was determined by measuring the ultraviolet (UV) absorbance of each well containing different concentration of pentamidine at $405 \mathrm{nM}$ over a time period of $340 \mathrm{~min}$. Solid line represents the sigmoidal dose-response fits (Equation (1)) for the data to obtain the values of $\mathrm{IC}_{50}, \mathrm{HS}$, and $\Delta \mathrm{Y}(\%)$. Given also are the standard error bars $( \pm 1 \mathrm{SE})$. 


\subsection{Pentamidine Isethionate Selectively Inhibits Human FXa and Plasmin in the Chromogenic Substrate Hydrolysis Assays}

To identify the molecular targets which represent the foundation for pentamidine isethionate effects on clot formation and lysis, we tested the inhibitory potential of this molecule towards human coagulation and fibrinolysis proteins including thrombin, FXa, FXIa, FXIIIa, and plasmin using 96-well platform and under the physiological conditions of $\mathrm{pH} 7.4$ and $37^{\circ} \mathrm{C}$ (Table 2). In chromogenic substrate hydrolysis assays [8,10-12], pentamidine dose-dependently inhibited FXa and plasmin with $\mathrm{IC}_{50}$ values of $10.4 \pm$ $0.8 \mu \mathrm{M}$ (Figure $4 \mathrm{~A}$ ) and $8.4 \pm 0.8 \mu \mathrm{M}$ (Figure 4B), respectively. Yet, it did not significantly inhibit thrombin or FXIa at the highest concentration tested of $100 \mu \mathrm{M}$ (inhibition was $<40 \%$ at $100 \mu \mathrm{M}$ ). In fluorescence-based, bi-substrate transglutamination assay [14,15], pentamidine isethionate did not inhibit human FXIIIa at the highest concentration tested of $50 \mu \mathrm{M}$. In fact, pentamidine did not inhibit the prototypical guinea pig transglutaminase at concentrations as high as $500 \mu \mathrm{M}$. Likewise, pentamidine isethionate also did not inhibit other serine proteases of bovine chymotrypsin and human neutrophil elastase at the highest concentrations tested of $1750 \mu \mathrm{M}$ and $100 \mu \mathrm{M}$, respectively. Yet, it inhibited bovine trypsin with $\mathrm{IC}_{50}$ values of $4.9 \pm 0.8 \mu \mathrm{M}$ under similar physiological conditions (Table 2).

Table 2. The inhibition profile of pentamidine isethionate towards several enzymes of relevance to coagulation, inflammation, and digestion. a)

\begin{tabular}{cccc}
\hline Enzyme & IC $_{\mathbf{5 0}}(\boldsymbol{\mu M})$ & HS & $\Delta$ Y $(\mathbf{\%})$ \\
\hline Thrombin & $\left.>100^{\mathrm{b}}\right)$ & $\mathrm{NA}^{\mathrm{c}}$ & $\mathrm{NA}$ \\
FXa & $\left.10.4 \pm 0.8^{\mathrm{d}}\right)$ & $0.97 \pm 0.07$ & $101.6 \pm 2.9$ \\
FXIa & $>100$ & $\mathrm{NA}$ & $\mathrm{NA}$ \\
FXIIIa & $>50$ & $\mathrm{NA}$ & $\mathrm{NA}$ \\
Plasmin & $8.4 \pm 0.8$ & $1.1 \pm 0.1$ & $98.0 \pm 3.3$ \\
Neutrophil Elastase & $>100$ & $\mathrm{NA}$ & $\mathrm{NA}$ \\
Trypsin & $4.9 \pm 0.8$ & $1.0 \pm 0.2$ & $116.8 \pm 7.4$ \\
Chymotrypsin & $>1750$ & $\mathrm{NA}$ & $\mathrm{NA}$ \\
\hline
\end{tabular}

Notes: ${ }^{\text {a) }}$ The $\mathrm{IC}_{50}, \mathrm{HS}$, and $\Delta \mathrm{Y}$ values were obtained following non-linear regression analysis of direct inhibition of the enzyme. Inhibition was monitored by spectrophotometric measurement of residual proteases activity (see Materials and Methods), ${ }^{b}$ No inhibition was observed up to concentrations as high as $100 \mu \mathrm{M}$ (thrombin, FXIa, and neutrophil elastase), $50 \mu \mathrm{M}$ (FXIIIa), or $1750 \mu \mathrm{M}$ (chymotrypsin), ${ }^{\text {c) }}$ Not applicable, ${ }^{\text {d) }}$ Errors represent \pm 1 S.E.
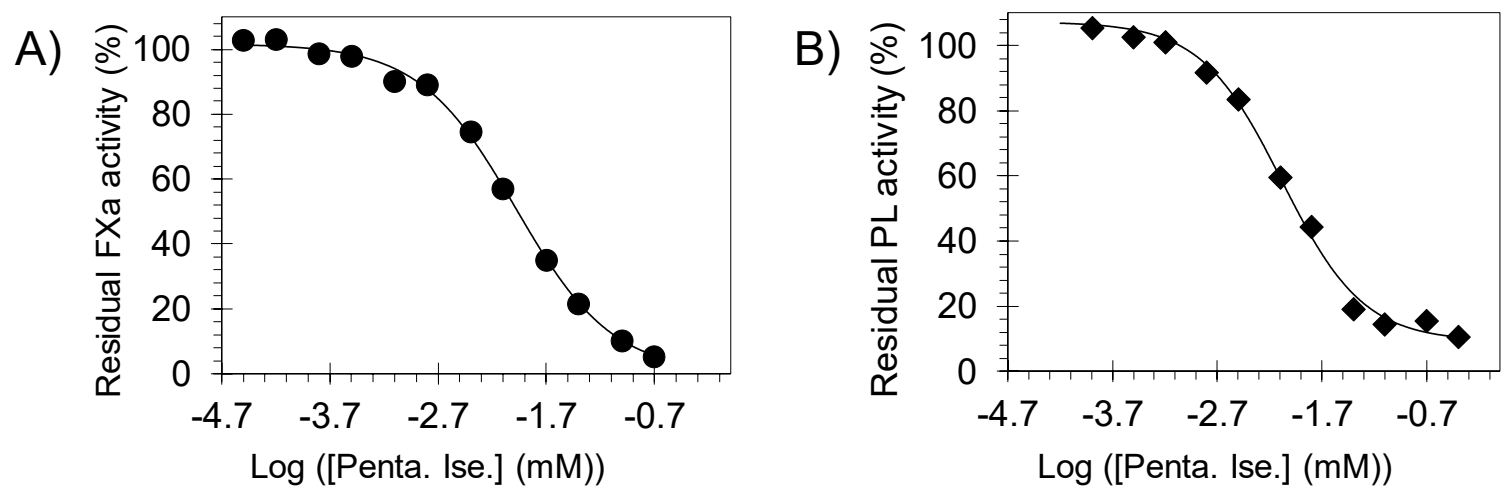

Figure 4. Direct inhibition of human FXa $(\bullet, A)$ and human plasmin $(\bullet, \mathbf{B})$ by pentamidine isethionate $(0-400 \mu \mathrm{M})$. Solid lines represent sigmoidal dose-response fit (Equation (1)) for the data to obtain the values of $\mathrm{IC}_{50}, \mathrm{HS}$, and $\Delta \mathrm{Y}(\%)$.

Overall, these results suggest that pentamidine is a relatively selective inhibitor of few serine proteases and that its effect on clot formation and lysis is because of its inhibition of FXa and plasmin, respectively, as depicted in Figure 5. 


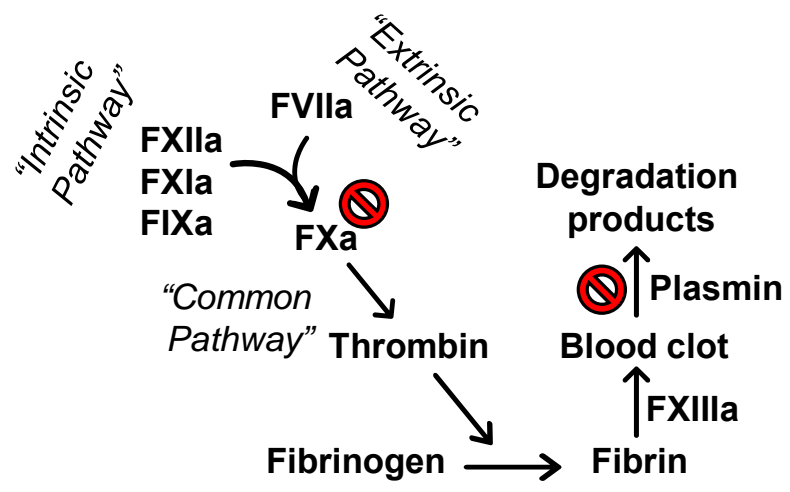

Figure 5. Representation of the coagulation (clot formation) and fibrinolysis (clot lysis) processes. The coagulation proceeds extrinsically (FVIIa) and/or intrinsically (FXIIa, FXIa, and FIXa). The two pathways further promote coagulation through the common coagulation pathway involving thrombin and FXa. Thrombin activates fibrinogen to fibrin which gets cross-linked by the action of FXIIIa. The resulting insoluble mesh of fibrin entraps activated platelets as well as red blood cells to form the blood clot. Following the clot formation, the clot undergoes plasmin-mediated lysis. The in vitro effect of pentamidine isethionate on coagulation and fibrinolysis is, in part, due to its inhibitory effects on FXa and plasmin, respectively.

\subsection{Michaelis-Menten Kinetics of FXa and Plasmin Inhibition by Pentamidine Isethionate}

To understand the basis for pentamidine's inhibitory potential towards human FXa, the kinetics of Spectrozyme FXa hydrolysis by FXa was measured at $\mathrm{pH} 7.4$ and $37^{\circ} \mathrm{C}$ in the presence of five different concentrations $(0-50 \mu \mathrm{M})$ of the substrate. As expected, the initial velocity varied in a hyperbolic manner with increasing concentration of the substrate at all concentrations of pentamidine (Figure 6A). The $\mathrm{K}_{\mathrm{M}}$ for Spectrozyme FXa in the absence of pentamidine was found to be $305.0 \pm 11.8 \mu \mathrm{M}$ (Table 3), which increased $\sim 2.3$-fold upon increasing the inhibitor's concentration to $50 \mu \mathrm{M}(690.2 \pm 63.1 \mu \mathrm{M})$. At the same time, the $\mathrm{V}_{\mathrm{MAX}}$ decreased $\sim 2.8$-fold from $169.4 \pm 3.6 \mathrm{mAU} / \mathrm{min}$ to $60.3 \pm 3.8 \mathrm{mAU} / \mathrm{min}$ for the same range of pentamidine concentration. These results indicate that pentamidine is a mixed inhibitor of FXa. In general, a mixed inhibitor may bind to both the free enzyme and the enzyme-substrate complex but has greater affinity for one form over the other. In this case, the affinity of Spectrozyme FXa to the enzyme decreases with increasing the concentration of pentamidine suggesting that the inhibitor may prefer to bind to the free enzyme, and thus, the inhibition kinetics mimic the kinetics of a competitive inhibitor.

A)

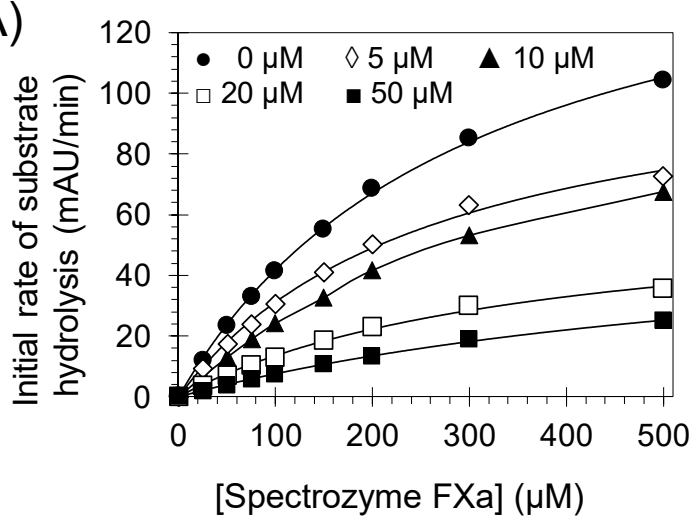

B)

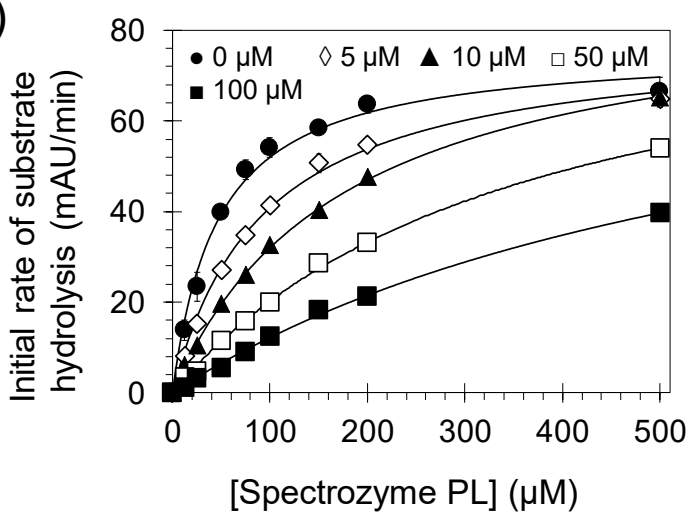

Figure 6. Michaelis-Menten kinetics of human FXa (A) and human plasmin (B) in the presence of different concentrations of pentamidine isethionate $(0-100 \mu \mathrm{M})$. The initial rate of hydrolysis at various substrate concentrations was measured spectrophotometrically in $\mathrm{pH} 7.4$ buffer at $37^{\circ} \mathrm{C}$. Solid lines represent the nonlinear regressional fits for the data using Equation (2) to yield $K_{M}$ and $V_{M A X}$. 
Table 3. Hydrolysis of the chromogenic substrate Spectrozyme FXa by human FXa and Spectrozyme PL by human plasmin in the presence of pentamidine isethionate. ${ }^{\text {a) }}$

\begin{tabular}{ccc}
\hline Inhibitor & \multicolumn{2}{c}{ Spectrozyme FXa } \\
\hline $\begin{array}{c}\text { Pentamidine } \\
\text { Isethionate }(\mu \mathbf{M})\end{array}$ & $\mathbf{K}_{\mathbf{M}}(\mu \mathbf{M})$ & $\mathbf{V}_{\mathbf{M A X}}(\mathbf{m A U} / \mathbf{m i n})$ \\
\hline 0 & $\left.305.0 \pm 11.8^{\mathrm{b}}\right)$ & $169.4 \pm 3.6$ \\
5 & $266.8 \pm 21.2$ & $114.3 \pm 4.7$ \\
10 & $410.3 \pm 18.2$ & $124.2 \pm 3.3$ \\
20 & $364.4 \pm 36.6$ & $63.1 \pm 3.6$ \\
50 & $690.2 \pm 63.1$ & $60.3 \pm 3.8$ \\
\hline Inhibitor & Spectrozyme PL \\
\hline Pentamidine & $\mathbf{K}_{\mathbf{M}}(\mu \mathbf{M})$ & $\mathbf{V}_{\mathbf{M A X}}(\mathbf{m A U} / \mathbf{m i n})$ \\
\hline 0 & $46.5 \pm 5.1$ & $76.2 \pm 2.5$ \\
10 & $92.9 \pm 6.2$ & $88.4 \pm 1.0$ \\
50 & $176.1 \pm 4.3$ & $92.9 \pm 3.2$ \\
100 & $358.9 \pm 21.3$ & $90.9 \pm 6.5$ \\
\hline
\end{tabular}

Note: ${ }^{\text {a) }} \mathrm{K}_{\mathrm{M}}$ and $\mathrm{V}_{\mathrm{MAX}}$ values of the chromogenic substrate hydrolysis by the corresponding enzymes (human FXa or plasmin) were measured as described under (Materials and Methods). mAU indicates milliabsorbance units, b) Error represents \pm 1 S.E.

Likewise, to understand the basis for pentamidine's inhibitory potential towards human plasmin, the kinetics of Spectrozyme PL hydrolysis by plasmin was measured at $\mathrm{pH} 7.4$ and $37{ }^{\circ} \mathrm{C}$ in the presence of five different concentrations $(0-100 \mu \mathrm{M})$ of the substrate. As with FXa, the initial velocity varied in a hyperbolic manner with increasing concentration of Spectrozyme PL at all concentrations of pentamidine (Figure $6 \mathrm{~B}$ ). The $\mathrm{K}_{\mathrm{M}}$ for Spectrozyme PL in the absence of pentamidine was found to be $46.5 \pm 5.1 \mu \mathrm{M}$ (Table 3), which increased 13.9-fold upon increasing the inhibitor's concentration to $100 \mu \mathrm{M}(645.5 \pm 68.17 \mu \mathrm{M})$. At the same time, the $\mathrm{V}_{\mathrm{MAX}}$ remained essentially constant for the same range of pentamidine concentration. These results indicate that pentamidine competitively inhibits the catalytic function of plasmin. Overall, pentamidine isethionate inhibits FXa and plasmin by targeting their active sites.

\subsection{Molecular Modeling Studies of Pentamidine Interaction with FXa and Plasmin}

To better understand the interactions between pentamidine and the two enzymes, FXa and plasmin, at atomic levels, we performed molecular modeling studies as described in the Materials and Methods. In the two exercises involving the two trypsin-like serine proteases, the best-docked structures indicate that one protonated amidino group of pentamidine forms a characteristic salt bridge to the side chain carboxylate group of D189 residue and a hydrogen bond to the carbonyl group of G219 residue in the S1 subsite of the active site of each enzyme (Figure 7). However, the other protonated amidino group appears to engage via another salt-bridge interaction with the carboxylate group of the side chain of E97 residue in FXa or via hydrogen bonds with the backbone carbonyl oxygen of R94 residue in plasmin. Overall, these results are in line with the fact that pentamidine is competitive inhibitor of FXa and plasmin and it disrupts their catalytic activities by targeting their active sites. 


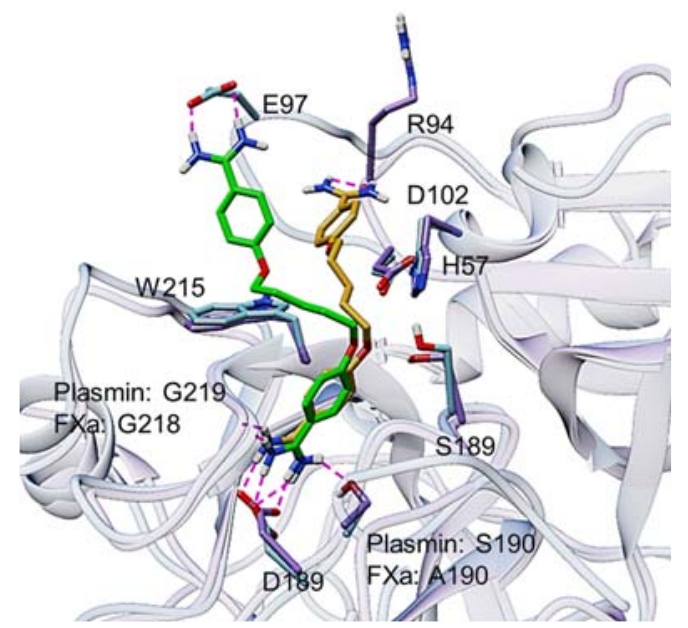

Figure 7. Glide-based docking and scoring study of pentamidine binding to human FXa (PDB ID: 1FAX) (sky blue protein and green inhibitor) and plasmin (PDB ID:1BUI) (purple protein and gold inhibitor). The key interactions are shown as dash lines and pentamidine is shown as sticks. For the two proteins, one of the inhibitor's protonated amidine groups is engaged with D189 residue.

\section{Discussion and Significance}

Considering the coagulation process, the results demonstrate that pentamidine significantly and dose-dependently doubles the clotting times APTT and PT at concentrations lower than $50 \mu \mathrm{M}$ under in vitro conditions, and it doubles the TT, albeit at concentrations higher than $150 \mu \mathrm{M}$. This suggests that pentamidine's in vitro effect on the coagulation process stems, in part, from targeting proteins belonging to the common coagulation pathway, particularly FXa which was inhibited dose-dependently and competitively by pentamidine with $\mathrm{IC}_{50}$ value of $\sim 10 \mu \mathrm{M}$ and efficacy of $\sim 100 \%$. Importantly, the effect of pentamidine at this concentration level appears to be specific due to the lack of effect on thrombin, FVIIa, FIXa, FXIa, FXIIa, or FXIIIa as indicated by studies involving deficient plasmas as well as the corresponding enzyme inhibition assays. Considering the fibrinolysis process, pentamidine significantly and dose-dependently inhibits the fibrinolysis process (clot lysis) in vitro settings by targeting plasmin. Pentamidine's inhibition potency and efficacy towards plasmin is substrate-dependent phenomena. Using the physiological substrate of plasmin i.e., cross-linked plasma clot, pentamidine inhibits plasmin with $\mathrm{IC}_{50}$ of $\sim 3.6 \mu \mathrm{M}$ and efficacy of $\sim 58 \%$. Yet, in the chromogenic substrate hydrolysis assay using the chromogenic tripeptide Spectrozyme PL, pentamidine competitively inhibits plasmin with $\mathrm{IC}_{50}$ value of $\sim 8.4 \mu \mathrm{M}$ and efficacy of $\sim 100 \%$.

Accordingly, the above findings along with the previously reported effects on platelet aggregation [7], may together account for the effect of pentamidine on coagulation and fibrinolysis in vitro. Important to mention here is that the relevance of these results to clinical practice is unknown. Generally, the means of plasma $\mathrm{C}_{\mathrm{MAX}}$ of pentamidine isethionate is $\leq 1 \mu \mathrm{M}$ [25-27] which suggests that pentamidine isethionate effects on coagulation and fibrinolysis may not be experienced by most of the patients. Yet, it should be noted that the likelihood of these adverse effects may potentially increase in patients having compromised renal or liver functions due to the involvement of these two organs in the metabolism and elimination of pentamidine and its metabolites [28].

Lastly, results reported here can be exploited to devise reversal strategies for pentamidine's hematological toxicities. The results may also inspire the design of new anti-trypanosomiasis and anti-leishmaniasis drugs that lack potential effects on coagulation and/or fibrinolysis. This is particularly important considering that the other antiprotozoal drug that is used to treat the early stage African trypanosomiasis i.e., suramin also affects the coagulation process via inhibiting the thrombin-induced fibrinogen clotting [29]. Furthermore, although it inhibits trypsin, the specificity of pentamidine continues to be significant given the lack of significant effect on a wide range of coagulation enzymes, 
neutrophil elastase, and chymotrypsin. Therefore, the pentamidine chemical scaffold can be exploited as a platform to design new effective anticoagulants by targeting human FXa or effective antifibrinolytics by targeting human plasmin for parenteral use in hospital settings.

Author Contributions: Conceptualization, R.A.A.H.; methodology, R.A.A.H., D.C., and M.M.; software, M.M.; validation, R.A.A.H.; formal analysis, R.A.A.H. and M.M.; investigation, R.A.A.H., D.C., and M.M.; resources, R.A.A.H.; data curation, R.A.A.H. and M.M.; writing-original draft preparation, R.A.A.H.; writing-review and editing, R.A.A.H.; visualization, R.A.A.H. and M.M.; supervision, R.A.A.H.; project administration, R.A.A.H.; funding acquisition, R.A.A.H.

Funding: Research reported was supported by NIGMS/NIH under award number SC3GM131986 to R.A.A.H. It was also supported by IDeA program from NIGMS/NIH under grant number P20 GM103424-17 to R.A.A.H. Also, D.C. is supported by the Health Resources and Services Administration of the U.S. Department of Health and Human Services under grant number D34HP00006. M.M. is supported by NIMHD/NIH under award number 2G12MD007595. The content is solely the responsibility of the authors and does not necessarily represent the official views of the funding institutions.

Conflicts of Interest: The authors declare no conflict of interest.

\section{References}

1. Khaw, M.; Panosian, C.B. Human antiprotozoal therapy: Past, present, and future. Clin. Microbiol. Rev. 1995, 8, 427-439. [CrossRef] [PubMed]

2. Goa, K.L.; Campoli-Richards, D.M. Pentamidine isethionate. A review of its antiprotozoal activity, pharmacokinetic properties and therapeutic use in Pneumocystis carinii pneumonia. Drugs 1987, 33, 242-258. [CrossRef] [PubMed]

3. Pohlig, G.; Bernhard, S.C.; Blum, J.; Burri, C.; Mpanya, A.; Lubaki, J.P.; Mpoto, A.M.; Munungu, B.F.; N'tombe, P.M.; Deo, G.K.; et al. Efficacy and safety of pafuramidine versus pentamidine maleate for treatment of first stage sleeping sickness in a randomized, comparator-controlled, international phase 3 clinical trial. PLoS Negl. Trop. Dis. 2016, 10, e0004363. [CrossRef] [PubMed]

4. Castro, J.G.; Morrison-Bryant, M. Management of Pneumocystis Jirovecii pneumonia in HIV infected patients: Current options, challenges and future directions. HIV AIDS (Auckl.) 2010, 2, 123-134. [CrossRef] [PubMed]

5. Pentamidine Isethionate. FDA Drug Label. Available online: https://www.accessdata.fda.gov/spl/data/589fcce2fa9a-4dc0-a79b-ae87cd024365/589fcce2-fa9a-4dc0-a79b-ae87cd024365.xml\#s10 (accessed on 12 May 2019).

6. Suzuki, T.; Takahashi, Y.; Yoshida, S.; Yamagishi, T.; Tateyama, M.; Tanaka, A.; Koshihara, K.; Matsumoto, K.; Fukue, H.; Yorifuji, H.; et al. HIV-1 seropositive hemophilia A complicated by disseminated intravascular coagulation syndrome and acute pancreatitis during treatment of Pneumocystis carinii pneumonia. Rinsho Ketsueki 1992,

mboxemph33, 1273-1278.

7. Kempin, S.J.; Jackson, C.W.; Edwards, C.C. In vitro inhibition of platelet function and coagulation by pentamidine isethionate. Antimicrob. Agents Chemother. 1977, 12, 451-454. [CrossRef]

8. Obaidullah, A.J.; Al-Horani, R.A. Discovery of chromen-7-yl furan-2-carboxylate as a potent and selective factor XIa inhibitor. Cardiovasc. Hematol. Agents Med. Chem. 2017, 15, 40-48. [CrossRef]

9. Al-Horani, R.A.; Gailani, D.; Desai, U.R. Allosteric inhibition of factor XIa. Sulfated non-saccharide glycosaminoglycan mimetics as promising anticoagulants. Thromb. Res. 2015, 136, 379-387. [CrossRef]

10. Afosah, D.K.; Al-Horani, R.A.; Sankaranarayanan, N.V.; Desai, U.R. Potent, selective, allosteric inhibition of human plasmin by sulfated non-saccharide glycosaminoglycan mimetics. J. Med. Chem. 2017, 60, 641-657. [CrossRef]

11. Al-Horani, R.A.; Karuturi, R.; White, D.T.; Desai, U.R. Plasmin regulation through allosteric, sulfated, small molecules. Molecules 2015, 20, 608-624. [CrossRef]

12. Al-Horani, R.A.; Ponnusamy, P.; Mehta, A.Y.; Gailani, D.; Desai, U.R. Sulfated pentagalloylglucoside is a potent, allosteric, and selective inhibitor of factor XIa. J. Med. Chem. 2013, 56, 867-878. [CrossRef] [PubMed]

13. Kummarapurugu, A.B.; Afosah, D.K.; Sankaranarayanan, N.V.; Navaz Gangji, R.; Zheng, S.; Kennedy, T.; Rubin, B.K.; Voynow, J.A.; Desai, U.R. Molecular principles for heparin oligosaccharide-based inhibition of neutrophil elastase in cystic fibrosis. J. Biol. Chem. 2018, 293, 12480-12490. [CrossRef] [PubMed] 
14. Al-Horani, R.A.; Karuturi, R.; Lee, M.; Afosah, D.K.; Desai, U.R. Allosteric inhibition of factor XIIIa. Non-saccharide glycosaminoglycan mimetics, but not glycosaminoglycans, exhibit promising inhibition profile. PLoS ONE 2016, 11, e0160189. [CrossRef] [PubMed]

15. Wu, Y.W.; Tsai, Y.H. A rapid transglutaminase assay for high-throughput screening applications. J. Biomol. Screen. 2006, 11, 836-843. [CrossRef] [PubMed]

16. Schrödinger. Schrödinger Release 2015-3: Glide; Schrödinger, LLC.: New York, NY, USA, 2015.

17. Brandstetter, H.; Kühne, A.; Bode, W.; Huber, R.; von der Saal, W.; Wirthensohn, K.; Engh, R.A. X-ray structure of active site-inhibited clotting factor $\mathrm{Xa}$. Implications for drug design and substrate recognition. J. Biol. Chem. 1996, 271, 29988-29992. [CrossRef] [PubMed]

18. Parry, M.A.; Fernandez-Catalan, C.; Bergner, A.; Huber, R.; Hopfner, K.P.; Schlott, B.; Gührs, K.H.; Bode, W. The ternary microplasmin-staphylokinase-microplasmin complex is a proteinase-cofactor-substrate complex in action. Nat. Struct. Biol. 1998, 5, 917-923. [CrossRef] [PubMed]

19. Sterling, T.; Irwin, J.J. ZINC 15-Ligand Discovery for Everyone. J. Chem. Inf. Model. 2015, 55, $2324-2337$. [CrossRef] [PubMed]

20. Harder, E.; Damm, W.; Maple, J.; Wu, C.; Reboul, M.; Xiang, J.Y.; Wang, L.; Lupyan, D.; Dahlgren, M.K.; Knight, J.L.; et al. OPLS3: A force field providing broad coverage of drug-like small molecules and proteins. J. Chem. Theory Comput. 2016, 12, 281-296. [CrossRef]

21. Al-Horani, R.A.; Afosah, D.K. Recent advances in the discovery and development of factor XI/XIa inhibitors. Med. Res. Rev. 2018, 38, 1974-2023. [CrossRef]

22. Roehrig, S.; Straub, A.; Pohlmann, J.; Lampe, T.; Pernerstorfer, J.; Schlemmer, K.H.; Reinemer, P.; Perzborn, E. Discovery of the novel antithrombotic agent 5-chloro-N-(\{(5S)-2-oxo-3-[4-(3-oxomorpholin-4-yl)phenyl]-1,3-oxazolidin-5-yl\}methyl)thiophene-2-carboxamide (BAY 59-7939): An oral, direct factor Xa inhibitor. J. Med. Chem. 2005, 48, 5900-5908. [CrossRef]

23. Samama, M.M.; Martinoli, J.L.; LeFlem, L.; Guinet, C.; Plu-Bureau, G.; Depasse, F.; Perzborn, E. Assessment of laboratory assays to measure rivaroxaban—An oral, direct factor Xa inhibitor. Thromb. Haemost. 2010, 103, 815-825. [PubMed]

24. Baglin, T.; Keeling, D.; Kitchen, S. British Committee for Standards in Haematology. Effects on routine coagulation screens and assessment of anticoagulant intensity in patients taking oral dabigatran or rivaroxaban: Guidance from the British Committee for Standards in Haematology. Br. J. Haematol. 2012, 159, 427-429. [CrossRef] [PubMed]

25. Conte, J.E., Jr.; Upton, R.A.; Phelps, R.T.; Wofsy, C.B.; Zurlinden, E.; Lin, E.T. Use of a specific and sensitive assay to determine pentamidine pharmacokinetics in patients with AIDS. J. Infect. Dis. 1986, 154, 923-929. [CrossRef] [PubMed]

26. Conte, J.E., Jr.; Upton, R.A.; Lin, E.T. Pentamidine pharmacokinetics in patients with AIDS with impaired renal function. J. Infect. Dis. 1987, 156, 885-890. [CrossRef] [PubMed]

27. Conte, J.E., Jr. Pharmacokinetics of intravenous pentamidine in patients with normal renal function or receiving hemodialysis. J. Infect. Dis. 1991, 163, 169-175. [CrossRef] [PubMed]

28. Bronner, U.; Gustafsson, L.L.; Doua, F.; Ericsson, O.; Miézan, T.; Rais, M.; Rombo, L. Pharmacokinetics and adverse reactions after a single dose of pentamidine in patients with Trypanosoma gambiense sleeping sickness. Br. J. Clin. Pharmacol. 1995, 39, 289-295. [CrossRef] [PubMed]

29. Monteiro, R.Q.; Campana, P.T.; Melo, P.A.; Bianconi, M.L. Suramin interaction with human alpha-thrombin: inhibitory effects and binding studies. Int. J. Biochem. Cell Biol. 2004, 36, 2077-2085. [CrossRef] [PubMed]

(C) 2019 by the authors. Licensee MDPI, Basel, Switzerland. This article is an open access article distributed under the terms and conditions of the Creative Commons Attribution (CC BY) license (http://creativecommons.org/licenses/by/4.0/). 